\title{
ESPACIALIDADE DOS FLUXOS MIGRATÓRIOS DOS MUNICÍPIOS DA BACIA DO RIO MUCURI EM MINAS GERAIS ${ }^{1}$
}

\author{
Ricardo Alexandrino Garcia* \\ Marcos Antônio Nunes \\ Aline Silva de Oliveira
}

O Vale do Mucuri é considerado uma das regiões-problema de Minas Gerais e por isso merece atenção especial de toda sociedade, especialmente do Governo de Minas Gerais e da União. Sabe-se que a porção centro-sul mineira, em geral, é mais rica e dinâmica, enquanto o seu antípoda, mais pobre. Os problemas de ordem econômica e social referem-se àqueles que caracterizam boa parte da porção centro-norte de Minas Gerais, representados por indicadores socioeconômicos, em alguns casos, inferiores à média estadual: PIB per capita, expectativa de vida, saneamento básico, etc. Em outros, lamentavelmente, superiores: taxa de mortalidade infantil, grau de analfabetismo, etc.

Longe de afirmar que a região do Mucuri é olvidada por pesquisadores, ela é, no mínimo, pouco pesquisada, ao se comparar com os estudos realizados para outras regiões mineiras. Esta assertiva encontra facilmente ecos no meio acadêmico (CERQUEIRA NETO, 2005). Em geral, os trabalhos realizados para a região tratam de temas pontuais, como o estudo da década de 1990, que se refere à colonização alemã no Mucuri (FJP, 1993). Por seu turno, o trabalho de Fonseca (1985) refere-se à história e ao povo de Nanuque. Na mesma perspectiva encontram-se os trabalhos de Ribeiro (2004), que estudou as imigrações e a expansão da agricultura nas matas do Mucuri. Algo pouco diferente, porém demasiadamente agregado, pode ser encontrado de Augusto (2007) que analisou os fluxos migratórios para as mesorregiões mineiras.

\footnotetext{
${ }^{1}$ Esse artigo integra-se aos objetivos de pesquisa financiada pela Fapemig intitulada "Diagnóstico socioambiental da Bacia do Mucuri em minas gerais: geohistória, (re)estruturações espaciais e desenvolvimento humano e econômico".

"Professor e pesquisador do Departamento de Geografia do IGC/UFMG.

-Pesquisador do Instituto de Geociências Aplicada de Minas Gerais IGA-MG.

•Pesquisadora do Centro de Sensoriamento Remoto - UFMG.

Cadernos do Leste

Artigos Cientificos

Belo Horizonte, Edição Especial, 2000 a 2008
} 
A elaboração de estudos direcionados ao desenvolvimento das regiões mais carentes como é o caso da Bacia do Rio Mucuri - e que visem sua integração às áreas e centros mais dinâmicos do país torna-se cada vez mais premente. Nesse sentido, caracterizar a espacialidade dos fluxos migratórios dos municípios que integram o Vale do Mucuri é o primeiro passo para a elaboração de diagnósticos socioeconômicos que levem em consideração a estrutura reticular que conforma essa parcela do território mineiro. E é esse o principal objetivo desse artigo.

\section{1- CARACTERIZAÇÃO TERRITORIAL DA BACIA DO RIO MUCURI}

A bacia hidrográfica do Mucuri localiza-se na Mesorregião do Vale do Mucuri, que compreende as microrregiões de Teófilo Otôni e Nanuque. Possui área de drenagem superior a 14,5 mil km² , sendo que mais de $90 \%$ dela situa-se em Minas Gerais, em sua porção E-NE. Seu principal rio é formado pela junção dos rios Mucuri do Norte e Mucuri do Sul. Os principais tributários da margem direita são o rio Todos os Santos e Uruçu; da margem esquerda, o rio Marambaia, o ribeirão do Gavião e o rio Pampã.

$\mathrm{Na}$ divisa dos estados do Espírito Santo e da Bahia estão seus tributários de menor extensão, porém é no Estado da Bahia que está o seu estuário. Em território mineiro a bacia envolve dezesseis municípios; nove deles situam-se integralmente na bacia, e os demais têm seus domínios territoriais parcialmente localizados, conforme o Quadro 1.

\section{Quadro 1. Minas Gerais: 2000. Municípios integrantes da Bacia do Mucuri}




\begin{tabular}{|c|c|c|c|}
\hline \multicolumn{4}{|c|}{ A) LOCALIZADOS INTEGRALMENTE NA BACIA } \\
\hline 1- CARLOS CHAGAS & \multicolumn{3}{|c|}{ 6- NOVO ORIENTE DE MINAS } \\
\hline 2- CATUJI & \multicolumn{2}{|r|}{ 7- PAVÃO } & \\
\hline 3- CRISÓLITA & \multicolumn{2}{|r|}{ 8- РOTÉ } & \\
\hline 4- ITAIPÉ & \multicolumn{2}{|r|}{ 9- TEÓFILO OTÔNI } & \\
\hline 5- LADAINHA & \multicolumn{2}{|c|}{ - } & \\
\hline \multicolumn{4}{|c|}{ B) LOCALIZADOS PARCIALMENTE NA BACIA } \\
\hline $\begin{array}{l}\text { B1) COM SEDE DENTRO DA } \\
\text { BACIA }\end{array}$ & $\begin{array}{l}\text { Área territorial } \cong \\
\text { na bacia }(\%)\end{array}$ & $\begin{array}{l}\text { B2) COM SEDE FORA DA } \\
\text { BACIA }\end{array}$ & $\begin{array}{l}\text { Área territorial } \cong \\
\text { na bacia }(\%)\end{array}$ \\
\hline 1- ÁGUAS FORMOSAS & 90 & 1- CARAÍ & 50 \\
\hline 2- FRONTEIRA DOS VALES & 50 & 2- MALACACHETA & 20 \\
\hline 3- NANUQUE & 90 & 3- UMBURATIBA & 70 \\
\hline 4- SERRA DOS AIMORÉS & 90 & - & - \\
\hline
\end{tabular}

Fonte: Setor de Limites - IGA

Desses municípios destaca-se o de Teófilo Otôni, primeiro núcleo urbano localizado às margens do rio Todos os Santos, no Alto Mucuri, e importante pólo regional mineiro. Teófilo Otôni surgiu em 1853, inicialmente denominado Filadélfia em homenagem aos ideais norte-americanos de república e liberdade (DUARTE, 2002). Apesar de oriunda de Carlos Chagas, Nanuque é a segunda cidade mais importante da região, sua origem está vinculada ao Porto de Santa Clara

O Mapa 1 traz informações sobre as extensões territoriais urbanas e rurais dos municípios que compõem a bacia hidrográfica do rio Mucuri. Tal como será melhor analisado mais adiante, apenas $0,5 \%$ do território em questão é formado por áreas urbanas, das quais se destacam as de Teófilo Otoni e Nanuque, os dois pólos urbanos da região. 
Mapa 1. Bacia do Rio Mucuri: 2008: Caracterização das áreas urbanas e rurais dos municípios que integram a Bacia Hidrográfica do Rio Mucuri.

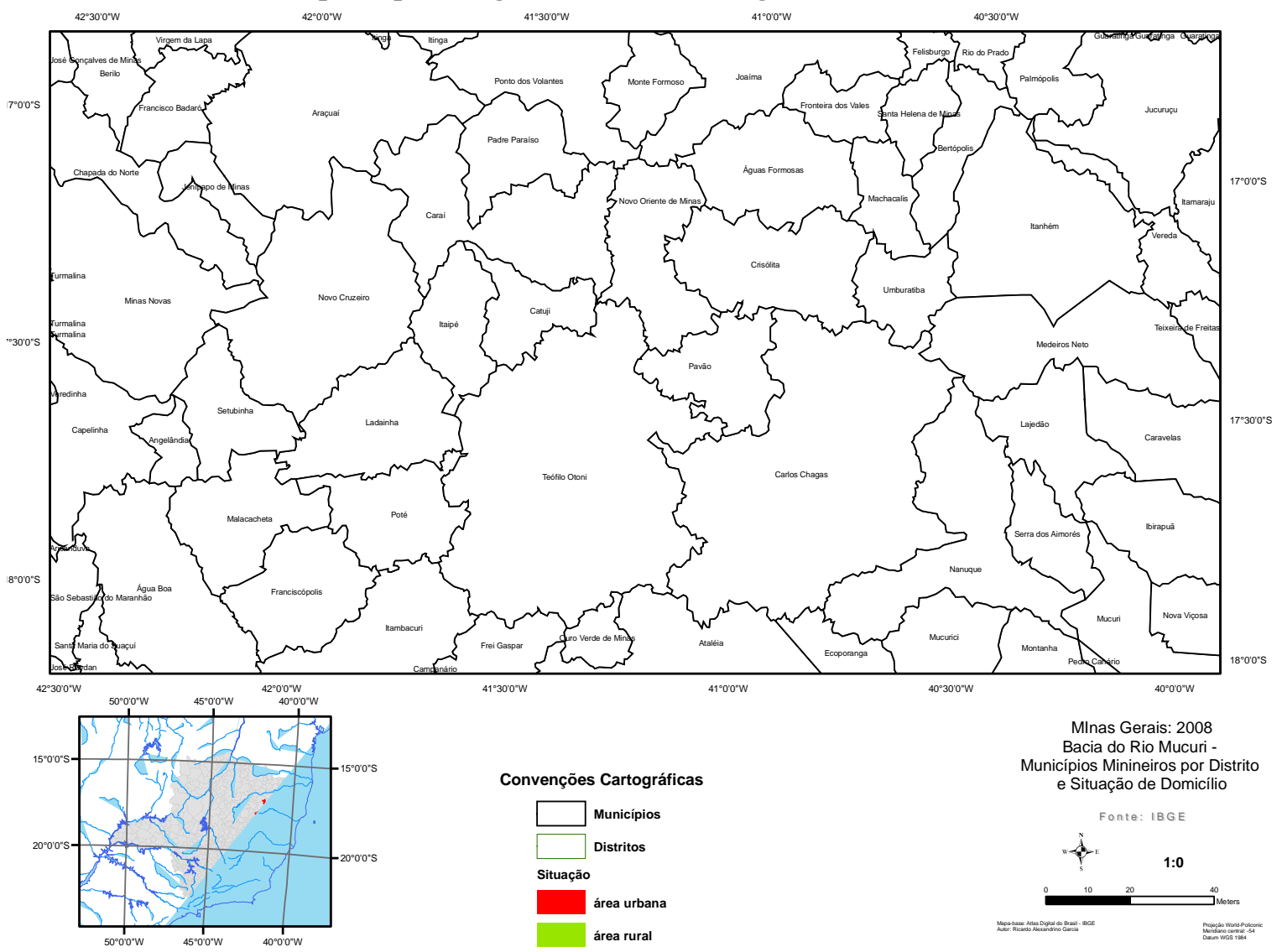

Fonte: IBGE. Malha de setores censitários rurais, 2000.

A Tabela 1 traz informações sobre a extensão territorial e os contingentes populacionais rurais e urbanos dos municípios que compõem a bacia hidrográfica do rio Mucuri. A análise preliminar dessas informações revela que apenas 0,5\% do território em questão é formado por áreas urbanas, ou seja, um percentual bem inferior ao observado no Brasil como um todo. Sua densidade populacional urbana, no entanto, é o dobro da observada em Minas Gerais, ou seja, 2775 habitantes por quilômetro quadrado, contra 1407 habitantes por quilômetro quadrado, segundo os dados de GARCIA \& MATOS, 2005. 
Tabela 1. Bacia do Rio Mucuri: 2007. Extensão

Territorial e Contingentes Populacionais Rurais e

\begin{tabular}{l|r|r|r}
\multicolumn{4}{c}{ Urbanos } \\
\hline & Urbana & Rural & \multicolumn{1}{c}{ Total } \\
\hline \hline Área $\left(\mathbf{K m}^{2}\right)$ & 82 & 16143 & 16225 \\
\hline Homens & 108541 & 55198 & 163739 \\
\hline Mulheres & 119038 & 50534 & 169572 \\
\hline Total & 227579 & 105732 & 333311 \\
\hline
\end{tabular}

Fonte: IBGE. Malha de setores censitários rurais, 2000 e

Contagem da População de 2007.

Um fenômeno inverso ocorre em relação a densidade demográfica total. Enquanto a do Estado, como um todo, é de aproximadamente 31 habitantes por quilômetro quadrado, a da bacia é de apenas 21 habitantes, aproximadamente. Os Mapas 2 e 3 ilustram melhor a dinâmica da distribuição espacial da população dos municípios que integram a Bacia Hidrográfica do Rio Mucuri e a distribuição espacial de sua densidade populacional, ambas segundo situação domiciliar. 
Mapa 2. Bacia do Rio Mucuri:2007: Distribuição espacial da população dos municípios que integram a Bacia Hidrográfica do Rio Mucuri, segundo situação domiciliar

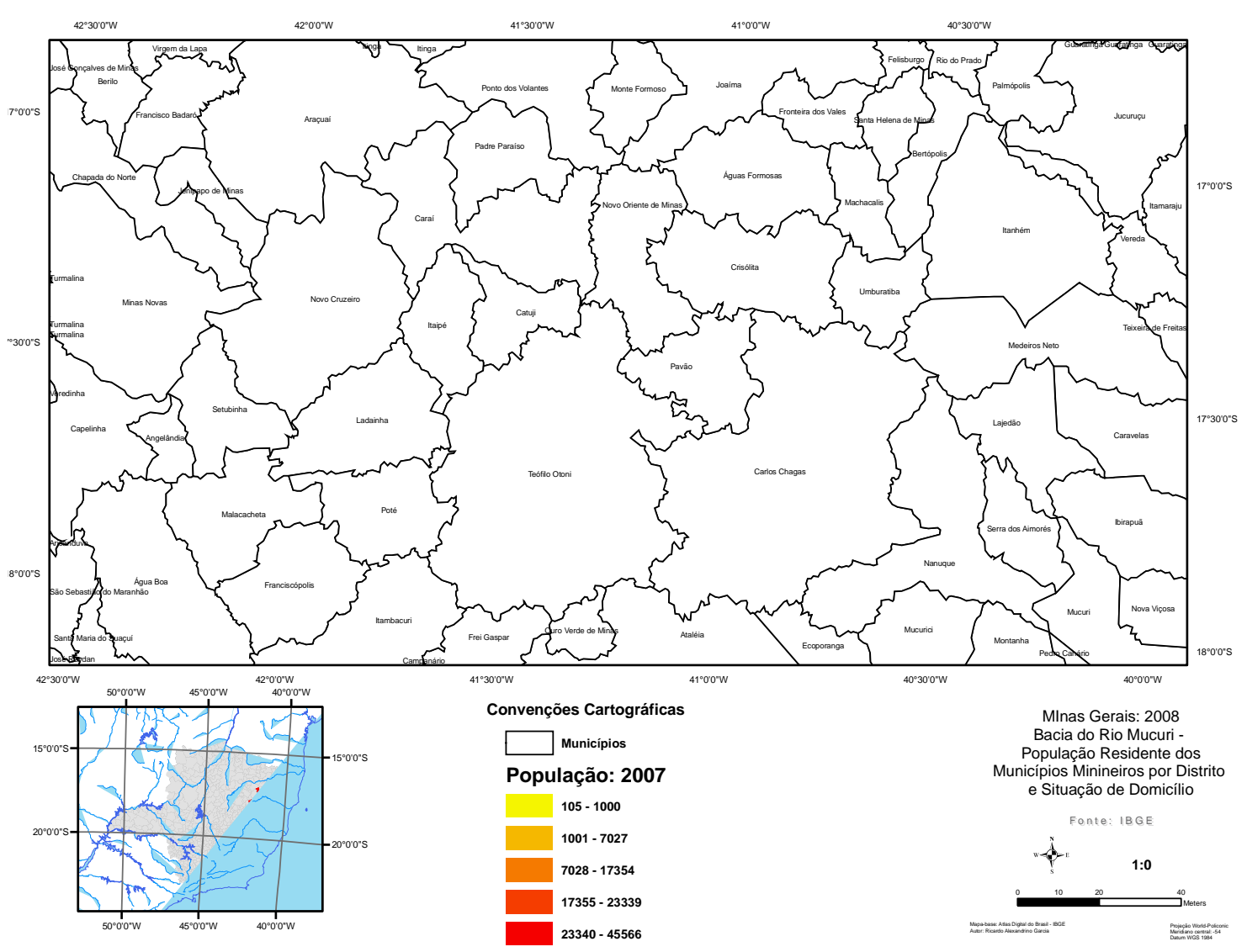

Fonte: IBGE. Malha de setores censitários rurais, 2000 e Contagem da População de 2007. 
Mapa 3. Bacia do Rio Mucuri: 2007: Distribuição espacial da densidade populacional, em habitantes por quilômetro quadrado, dos municípios que integram a Bacia Hidrográfica do Rio Mucuri, segundo situação domiciliar.

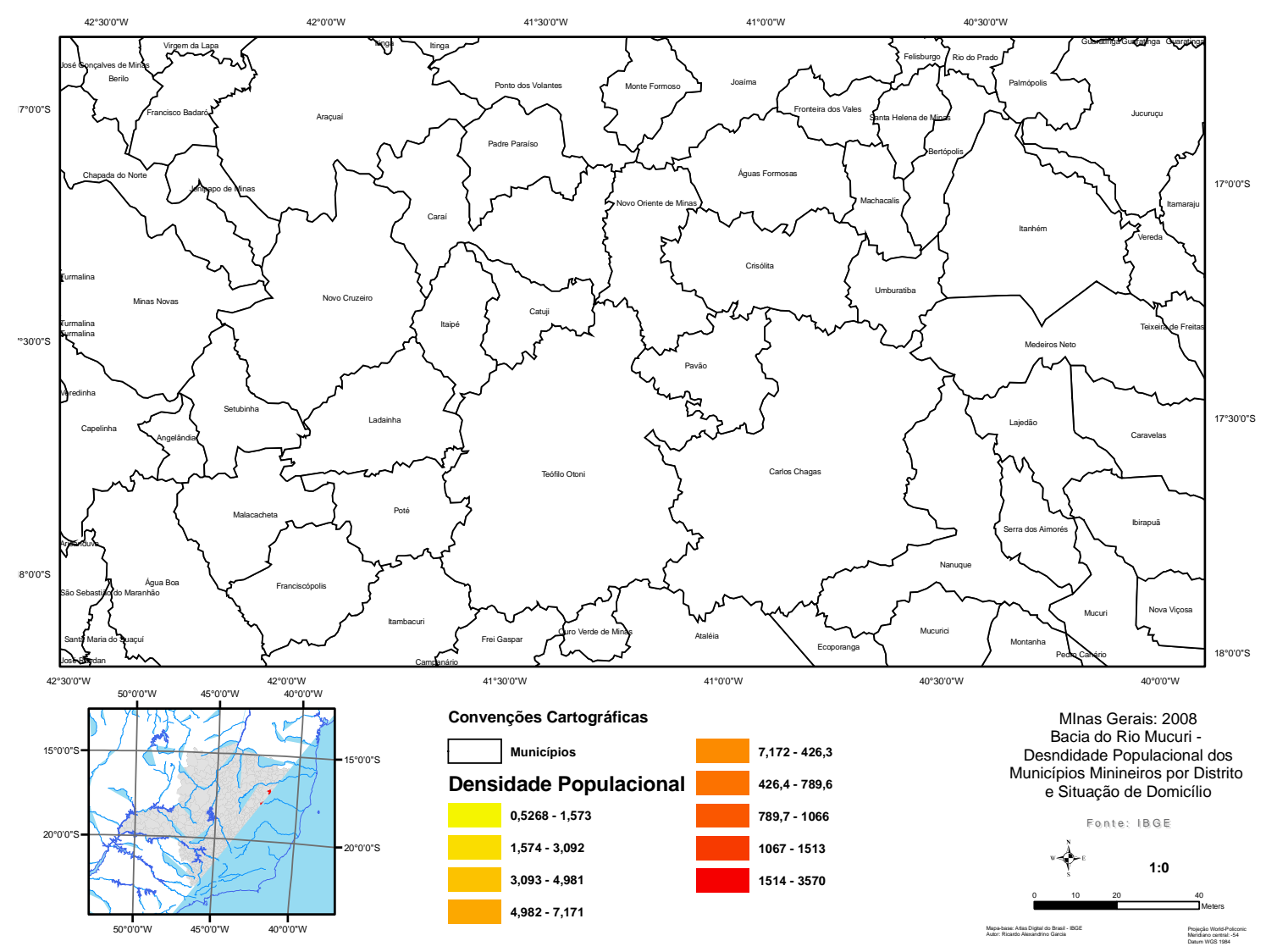

Fonte: IBGE. Malha de setores censitários rurais, 2000 e Contagem da População de 2007.

\section{2- DESCRIÇÃO E ANÁLISE DA DINÂMICA MIGRATÓRIA RECENTE DOS MUNICÍPIOS}

Os micro dados dos Censos Demográficos de 1980, 1991 e 2000 produzem boas estatísticas de movimentos migratórios intermunicipais e permitem que esses movimentos 
possam ser ponderados e/ou controlados, segundo diversas informações socioeconômicas tais como idade, renda, escolaridade, etc. - dos indivíduos recenseados.

Os movimentos populacionais dos quinquênios 1986/1991 e 1995/2000 foram estimados com base no quesito migração de data-fixa dos Censos Demográficos de 1991 e 2000. Essa variável indica o local de residência exatamente cinco anos atrás da data de referência da pesquisa. Os dados do Censo de 1980 não permitem estimar o número de imigrantes e emigrantes de data-fixa. Entretanto, os microdados desse Censo permitem estimar o número de imigrantes e emigrantes de ultima etapa do último quinquênio - que leva em consideração a localidade de residência anterior do migrante com menos de 5 anos de residência na localidade atual - entre cada par de municípios. Tais estimativas constituem-se em uma boa aproximação da migração de data fixa (RIGOTTI, 1999). ${ }^{2}$

Os municípios de Águas Formosas, Carai, Carlos Chagas, Malacacheta Fronteira dos Vales, Nanuque, Pavão e Teófilo Otoni vêm demonstrando, desde os anos 70, perdas populacionais, principalmente nas áreas rurais. Essa tendência pode ser observada a partir dos dados da Tabela 2. Grosso modo, o volume de imigração, nos períodos qüinqüenais de 1975/1980, 1986/1991 e 1995/2000, sempre estiveram abaixo o volume de emigração, o que acusa saldos migratórios negativos dessas localidades para esses qüinqüênios. Em relação às taxas líquidas de migração, nota-se que houve uma diminuição das perdas relativas desde o período de 1975/1980 até 1995/2000 e o processo contrário ocorreu para o quinquênio de 1995/2000, exceto em Carai, Fronteira dos Vales e Teófilo Otoni

O município de Itaipé, Poté e Umburatiba também vieram apresentando perdas populacionais desde a década de 70, mas na década de 90, o esse processo parece se inverter. A análise das taxas líquidas de migração revela que, no município de Itaipé, houve um aumento das perdas relativas do período de 1975/1980 para 1986/1991 e o processo contrário ocorreu para o quinquênio de 1995/2000; em Pote e Umburatiba, houve uma

\footnotetext{
${ }^{2}$ Todos os migrantes de data fixa, que correspondem a exatamente 5 anos atrás, são também migrantes de última etapa do quinquênio, No entanto, parte destes não são de data fixa em relação à área de estudo: 1 - os imigrantes de última etapa, que no início do quinquênio residia na localidade de residência atual (migrantes retornados plenos); 2 - os emigrantes de última etapa, cuja localidade de residência no início do quinquênio (data fixa) era diferente daquela de residência imediatamente anterior (CARVALHO \& GARCIA, 2002).
}

Cadernos do Leste

Artigos Cientificos

Belo Horizonte, Edição Especial, 2000 a 2008 
diminuição das perdas relativas do período de 1975/1980 para 1986/1991 e, no quinquênio de 1995/2000, ocorreram ganhos populacionais. Com relação aos municípios de Catuji e Crisólita, pôde-se apenas estimar os dados de migração para o último quinquênio da década de 90, pois nos anteriores eles não se haviam emancipados. Eles seguem, contudo, a tendência geral do restante dos municípios da Bacia e também apresentam perdas populacionais. O único município que apresentou ganhos populacionais durante todos os quinquênios considerados nesse estudo foi o município da Serra dos Aimorés. Embora o saldo migratório tenha diminuído entre os quinquênios de 1986/1991 e 1995/2000, sua taxa líquida de migração dobrou no mesmo período, tal como pode ser observado na Tabela 2 
Tabela 2. Municípios da bacia do rio mucuri: 1975/2000. Imigrantes e emigrantes intermunicipais e taxas liquidas de migração quinquenais: 1975/1980, 1986/1991 e $1995 / 2000$.

\begin{tabular}{|c|c|c|c|c|}
\hline Quinquenios & Emigrantes & Imigrantes & Saldo Migratório & Taxa Liquida de Migração \\
\hline \multicolumn{5}{|c|}{ Águas Formosas } \\
\hline $1975 / 1980$ & 4989 & 1277 & -3712 & $-0,14$ \\
\hline 1986/1991 & 3507 & 1548 & -1958 & $-0,08$ \\
\hline $1995 / 2000$ & 4218 & 2057 & -2161 & $-0,1$ \\
\hline \multicolumn{5}{|c|}{ Carai } \\
\hline $1975 / 1980$ & 1300 & 423 & -877 & $-0,48$ \\
\hline 1986/1991 & 1524 & 779 & -745 & $-0,03$ \\
\hline $1995 / 2000$ & 3289 & 1749 & -1539 & $-0,06$ \\
\hline \multicolumn{5}{|c|}{ Carlos Chagas } \\
\hline $1975 / 1980$ & 7028 & 1521 & -5507 & $-0,16$ \\
\hline 1986/1991 & 5423 & 2045 & -3378 & $-0,12$ \\
\hline $1995 / 2000$ & 4139 & 2222 & -1917 & $-0,08$ \\
\hline \multicolumn{5}{|c|}{ Fronteira dos Vales } \\
\hline $1975 / 1980$ & 688 & 69 & -619 & $-0,1$ \\
\hline 1986/1991 & 391 & 201 & -190 & $-0,03$ \\
\hline $1995 / 2000$ & 724 & 460 & -264 & $-0,05$ \\
\hline \multicolumn{5}{|c|}{ Malacacheta } \\
\hline $1975 / 1980$ & 5702 & 1021 & -4681 & $-0,11$ \\
\hline 1986/1991 & 4670 & 847 & -3822 & $-0,09$ \\
\hline $1995 / 2000$ & 3293 & 1070 & -2222 & $-0,1$ \\
\hline \multicolumn{5}{|c|}{ Nanuque } \\
\hline $1975 / 1980$ & 14814 & 7191 & -7623 & $-0,15$ \\
\hline 1986/1991 & 8626 & 4383 & -4243 & $-0,08$ \\
\hline $1995 / 2000$ & 10629 & 7132 & -3497 & $-0,08$ \\
\hline \multicolumn{5}{|c|}{ Pavão } \\
\hline $1975 / 1980$ & 2736 & 444 & -2292 & $-0,17$ \\
\hline $1986 / 1991$ & 1580 & 165 & -1416 & $-0,08$ \\
\hline $1995 / 2000$ & 1443 & 649 & -794 & $-0,08$ \\
\hline \multicolumn{5}{|c|}{ Teófilo Otoni } \\
\hline $1975 / 1980$ & 30928 & 9825 & -21133 & $-0,14$ \\
\hline 1986/1991 & 18368 & 9764 & -8604 & $-0,057$ \\
\hline $1995 / 2000$ & 23740 & 13344 & -10396 & $-0,07$ \\
\hline \multicolumn{5}{|c|}{ Itaipé } \\
\hline $1975 / 1980$ & 1072 & 1024 & -48 & $-0,003$ \\
\hline $1986 / 1991$ & 1556 & 1328 & -228 & $-0,01$ \\
\hline $1995 / 2000$ & 1303 & 1322 & 18 & 0 \\
\hline \multicolumn{5}{|c|}{ Poté } \\
\hline $1975 / 1980$ & 1775 & 511 & -1264 & $-0,07$ \\
\hline $1986 / 1991$ & 1205 & 1026 & -179 & $-0,01$ \\
\hline $1995 / 2000$ & 2058 & 2330 & 272 & 0,02 \\
\hline \multicolumn{5}{|c|}{ Serra dos Aimorés } \\
\hline $1975 / 1980$ & 1530 & 1538 & 8 & 0 \\
\hline 1986/1991 & 1073 & 1240 & 167 & 0,01 \\
\hline $1995 / 2000$ & 1680 & 1824 & 144 & 0,02 \\
\hline \multicolumn{5}{|c|}{ Umburatiba } \\
\hline $1975 / 1980$ & 688 & 69 & -619 & $-0,1$ \\
\hline $1986 / 1991$ & 391 & 201 & -190 & $-0,03$ \\
\hline $1995 / 2000$ & 434 & 547 & 113 & 0,04 \\
\hline \multicolumn{5}{|c|}{ Catuji } \\
\hline $1995 / 2000$ & 1095 & 667 & -427 & $-0,05$ \\
\hline \multicolumn{5}{|c|}{ Crisólita } \\
\hline $1995 / 2000$ & 1197 & 828 & -369 & $-0,04$ \\
\hline
\end{tabular}

Fonte: IBGE. Censos Demográficos de 1980, 1991 e 2000 (elaboração do autor).

Cadernos do Leste

Artigos Cientificos

Belo Horizonte, Edição Especial, 2000 a 2008 


\section{3- A ESPACIALIDADE DOS FLUXOS MIGRATÓRIOS DOS MUNICÍPIOS DA BACIA DO RIO MUCURI}

A distribuição espacial dos fluxos migratórios dos municípios da Bacia do Rio Mucuri está ilustrada nos Mapa 4 a 18, sua análise revela uma grande concentração desses fluxos em torno das regiões mais próximas aos municípios, no centro e em torno do Estado de Minas Gerais, predominantemente, mas com algumas especificidades: em relação ao município de Águas Formosas (Mapa 4), a análise revela que os movimentos que mais contribuíram para essa concentração em torno do município são os fluxos de emigrantes, que ocorreram principalmente nas décadas de 70 e 80 . Nas mesmas décadas observa-se que houve uma concentração de fluxos de emigrantes que foram para o sul de Minas Gerais e para a região noroeste de São Paulo. Já na década de 90 nota-se que ocorreram fluxos de emigrantes que se dirigiram para o centro-sul de Minas Gerais e para o estado do Pará.

Cadernos do Leste

Artigos Cientificos

Belo Horizonte, Edição Especial, 2000 a 2008 
Mapa 4. Brasil: 1975/2000. Emigrantes e imigrantes do município de águas formosas, nos quinquênios 1975/1980, 1986/1991 e 1995/2000, segundo localidades de origem e de destino.

Cadernos do Leste

Artigos Cientificos

Belo Horizonte, Edição Especial, 2000 a 2008 


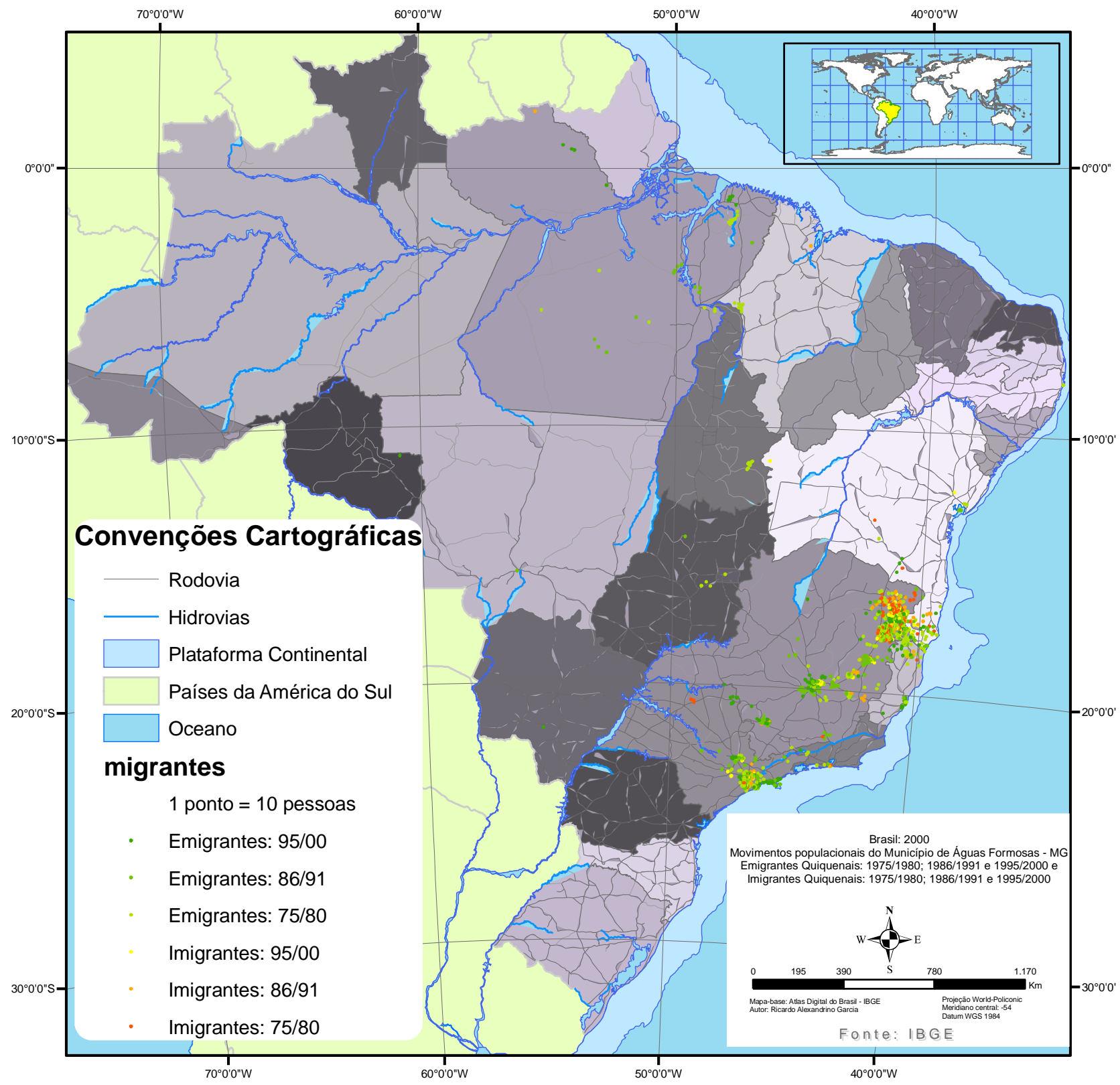

Fonte: ibge. censos demográficos de 1980, 1991 e 2000 (elaboração do autor).

Em Carai (Mapa 5), algo semelhante ocorre, mas nota-se que na década de 90 ocorreram muitos fluxos de emigrantes que se dirigiram para o centro do estado e redondezas e para outras regiões do país, principalmente para região noroeste de São Paulo e sul do

Cadernos do Leste Artigos Cientificos 
Espírito Santo. Em menor intensidade nota-se a ocorrência desses fluxos também para os estados do Piauí e Ceará. Na análise dos fluxos migratórios de Carlos Chagas (Mapa 6), os movimentos que mais contribuem para a concentração em torno do município são os fluxos de emigrantes, que ocorreram principalmente nas décadas de 70 e 80, com uma concentração menor de fluxos de imigrantes que também ocorreram nessas décadas. Nota-se que na década de 90 ocorreram muitos fluxos de emigrantes que se dirigiram para o centro do estado e redondezas e para outras regiões do país, principalmente para região norte, estados de Rondônia e Pará. No município de Fronteira dos Vales (Mapa 7), observa-se que nas décadas de 70 e 80 ocorreram muitos fluxos de emigrantes e imigrantes que se dirigiram e se destinaram para o sul de Minas Gerais e para os municípios mais ao norte de Fronteiras do Vale e noroeste de São Paulo. Na década de 90 observa-se que houve fluxos na região central do Estado e nas décadas de 70 e 80, houve fluxos de imigrantes que se destinaram do sul do da Bahia.

O Mapa 8 traz a distribuição espacial dos fluxos migratórios do município de Itaipé e sua análise revela que na década de 90 ocorreram muitos fluxos de emigrantes que se dirigiram para o centro do estado e na década de 70 e 80 se dirigiram para o oeste de São Paulo. No tocante à Malacacheta, verifica-se que nas décadas de 70 e 80 ocorreram muitos fluxos de emigrantes que se dirigiram para o sul e centro do Estado, para Rondônia, para região central de Mato Grosso e Pará, bem como fluxos de imigração, do sul da Bahia e do centro de Mato Grosso e alguns também que se destinaram do estado de São Paulo (Mapa 9).

A distribuição espacial dos fluxos migratórios referente ao município de Nanuque está ilustrada no Mapa 10, sua análise revela que também nas décadas de 70 e 80 ocorreram fluxos de imigração espalhados por todo território mineiro, com uma concentração maior no sul da Bahia e nas regiões fronteiriças entre Minas e Espírito Santo; já na década de 90 os fluxos de imigrantes ficaram mais concentrados em torno de da municipalidade. Em Pavão, nota-se que na década de 90 ocorreram muitos fluxos de emigrantes que se dirigiram para o centro do estado e redondezas; muitos fluxos de emigrantes da década de 70 e 80 se dirigiram para o sul de Minas, Noroeste de São Paulo, Para e Rondônia e Espírito Santo, bem como fluxos de

Cadernos do Leste

Artigos Cientificos

Belo Horizonte, Edição Especial, 2000 a 2008 
emigração em direção à Goiás, Distrito federal e no sul da Bahia (Mapa 11). A análise dos fluxos de Pote indica que na década de 90 ocorreram muitos fluxos de emigrantes e de imigrantes que se dirigiram e se destinaram do Espírito Santo, das regiões fronteiriças entre esse Estado e Minas Gerais e do centro de Minas com alguns fluxos espalhados por todo o Estado (Mapa 12).

No município de Serra dos Aimorés, entre as décadas de 70 e 80, ocorreram muitos fluxos de emigrantes e imigrantes que se dirigiram para o centro e sul de Minas Gerais, para o norte do Espírito Santo, e noroeste de São Paulo, e alguns se concentraram também ao redor da municipalidade; já os movimentos que mais contribuem para essa concentração em torno do município são os fluxos de emigrantes e imigrantes da década de 90; são observados também fluxos de migrantes espalhados pelo nordeste, pelos estados de Rondônia, Pará, Goiás e distrito federal (Mapa13). 
Mapa 5. Brasil: 1975/2000. Emigrantes e imigrantes do município de Caraí, nos quinquênios 1975/1980, 1986/1991 e 1995/2000, segundo localidades de origem e de destino.

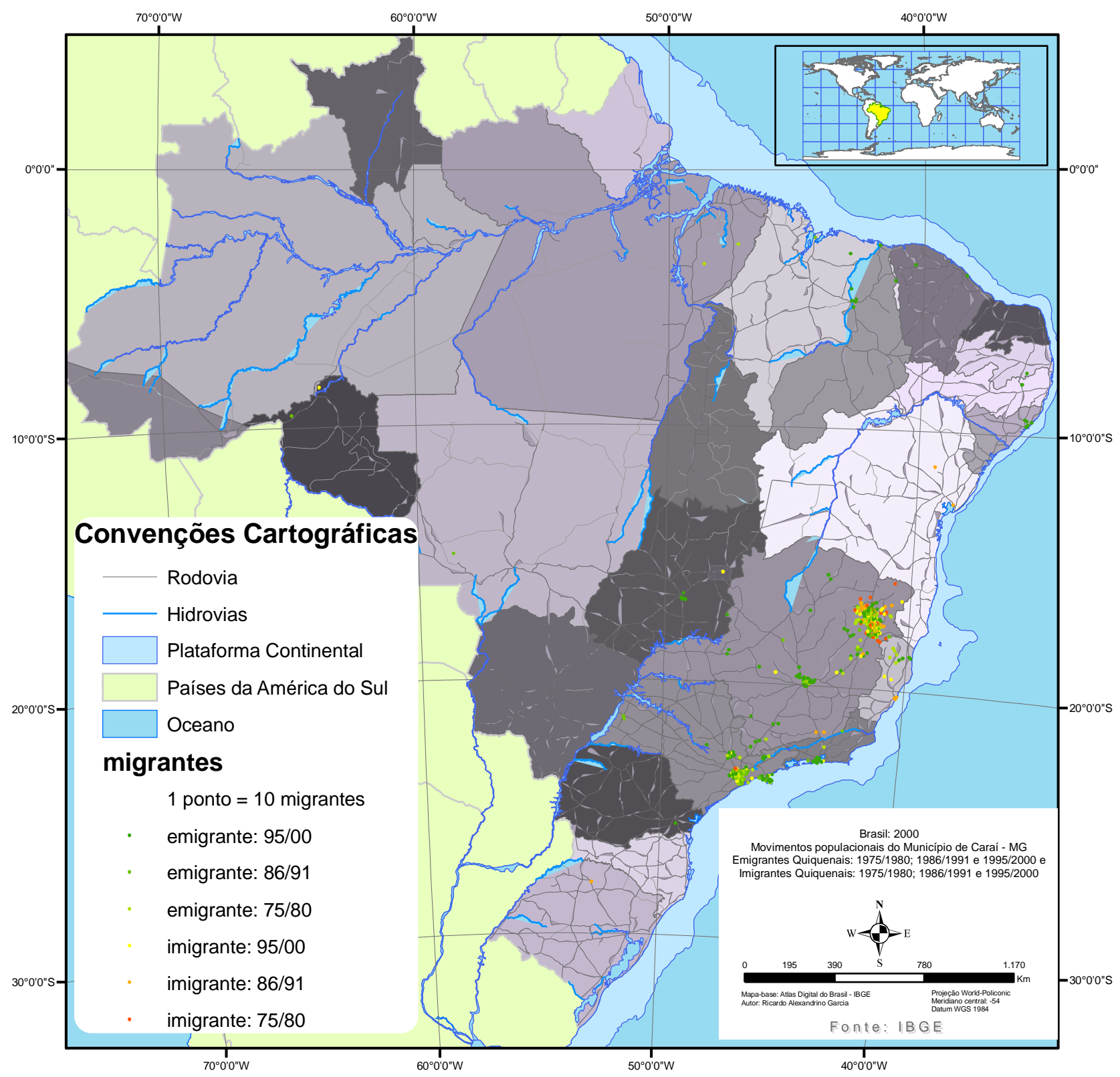

Fonte: IBGE. Censos demográficos de 1980, 1991 e 2000 (elaboração do autor).

Cadernos do Leste

Artigos Cientificos

Belo Horizonte, Edição Especial, 2000 a 2008 
Mapa 6. Brasil: 1975/2000. Emigrantes E Imigrantes Do Município De Carlos Chagas, Nos Quinquênios 1975/1980, 1986/1991 E 1995/2000, Segundo Localidades De Origem E De Destino. 


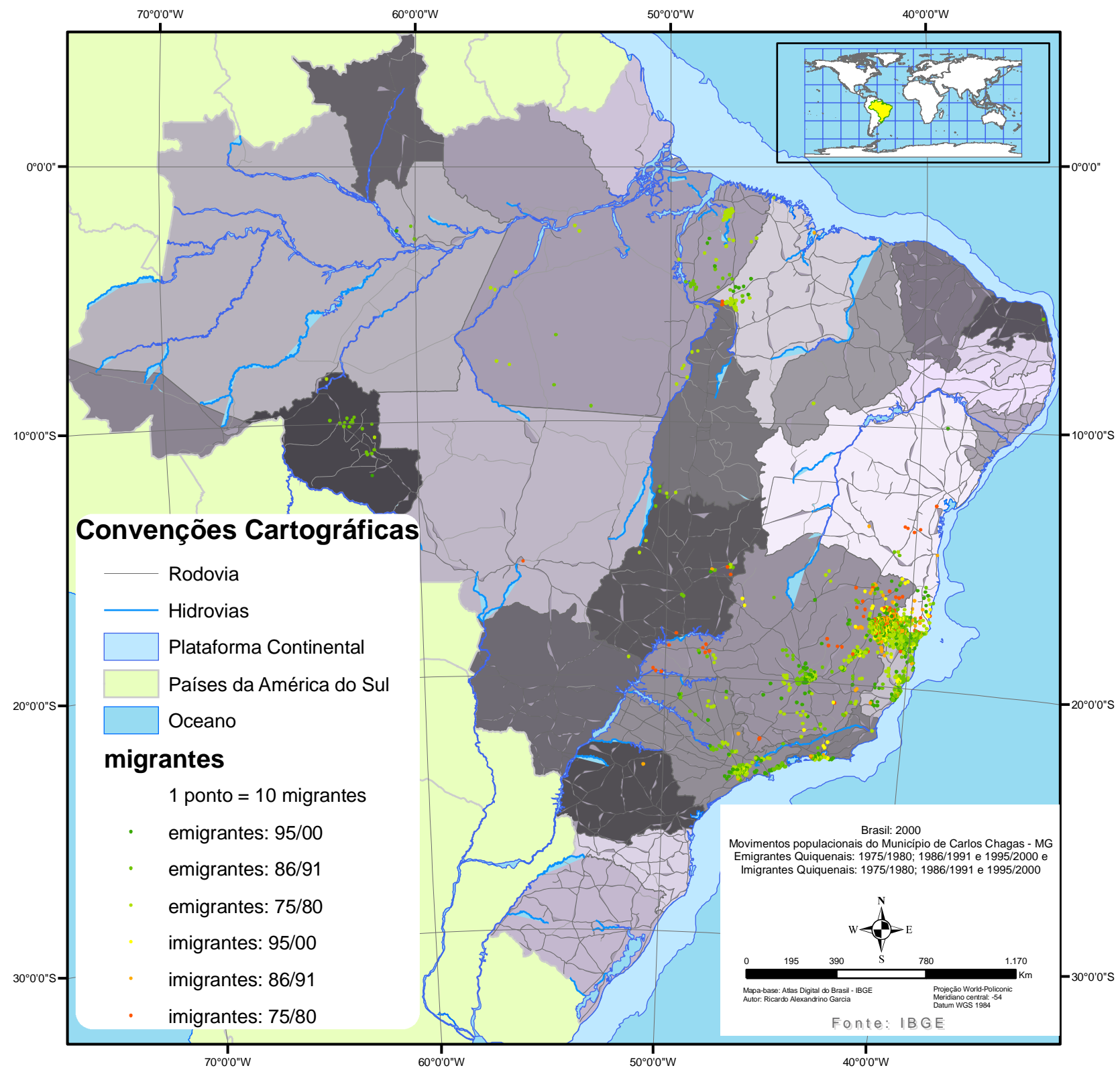

Fonte: IBGE. Censos demográficos de 1980, 1991 e 2000 (elaboração do autor).

Cadernos do Leste

Artigos Cientificos

Belo Horizonte, Edição Especial, 2000 a 2008 
Mapa 7. Brasil: 1975/2000. Emigrantes E Imigrantes Do Município De Fronteira Dos Vales, Nos Quinquênios 1975/1980, 1986/1991 E 1995/2000, Segundo Localidades De Origem E De Destino.



Fonte: IBGE. Censos demográficos de 1980, 1991 e 2000 (elaboração do autor).

Cadernos do Leste Artigos Científicos 
Mapa 8. Brasil: 1975/2000. Emigrantes e imigrantes do município de Itaipé, nos qüinqüênios 1975/1980, 1986/1991 e 1995/2000, segundo localidades de origem e de destino.

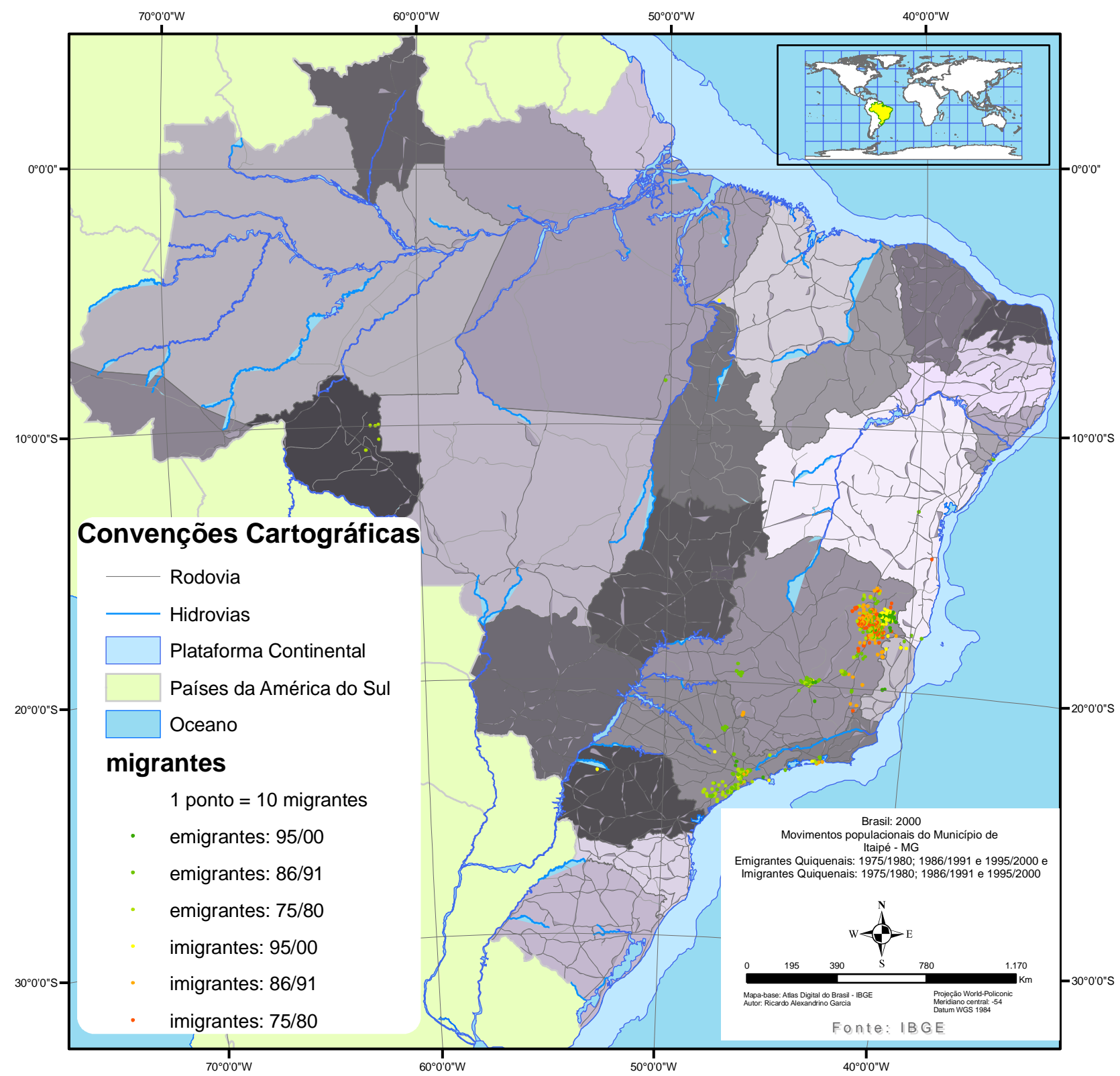

Fonte: IBGE. Censos demográficos de 1980, 1991 e 2000 (elaboração do autor).

Cadernos do Leste Artigos Científicos 
Mapa 9. Brasil: 1975/2000. Emigrantes E Imigrantes Do Município De Malacacheta, Nos Quinquênios 1975/1980, 1986/1991 E 1995/2000, Segundo Localidades De Origem E De

Destino.

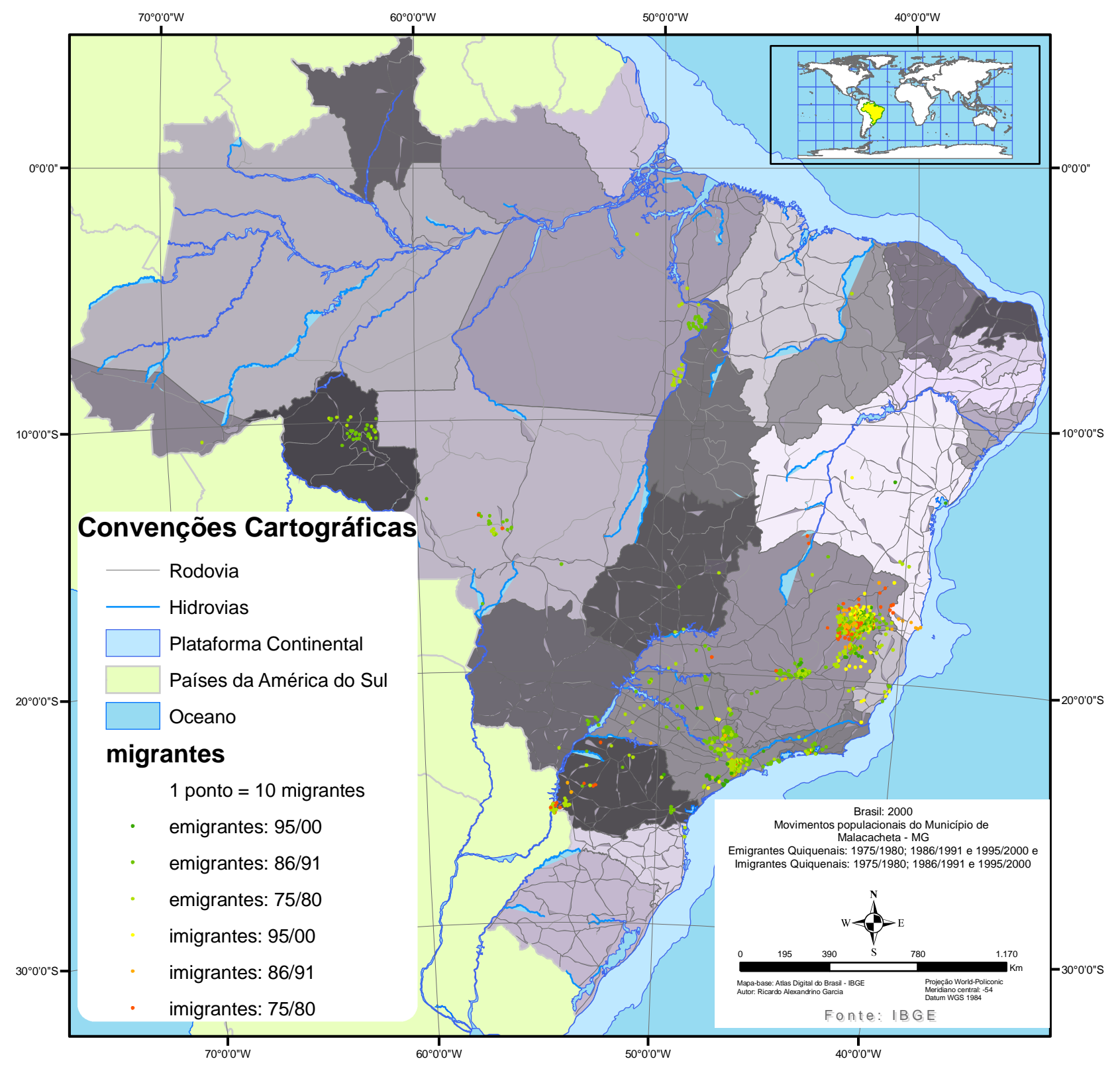

Fonte: IBGE. Censos demográficos de 1980, 1991 e 2000 (elaboração do autor).

Cadernos do Leste

Artigos Cientificos

Belo Horizonte, Edição Especial, 2000 a 2008 
Mapa 10. Brasil: 1975/2000. Emigrantes E Imigrantes Do Município De Nanuque, Nos Quinquênios 1975/1980, 1986/1991 E 1995/2000, Segundo Localidades De Origem E De Destino. 


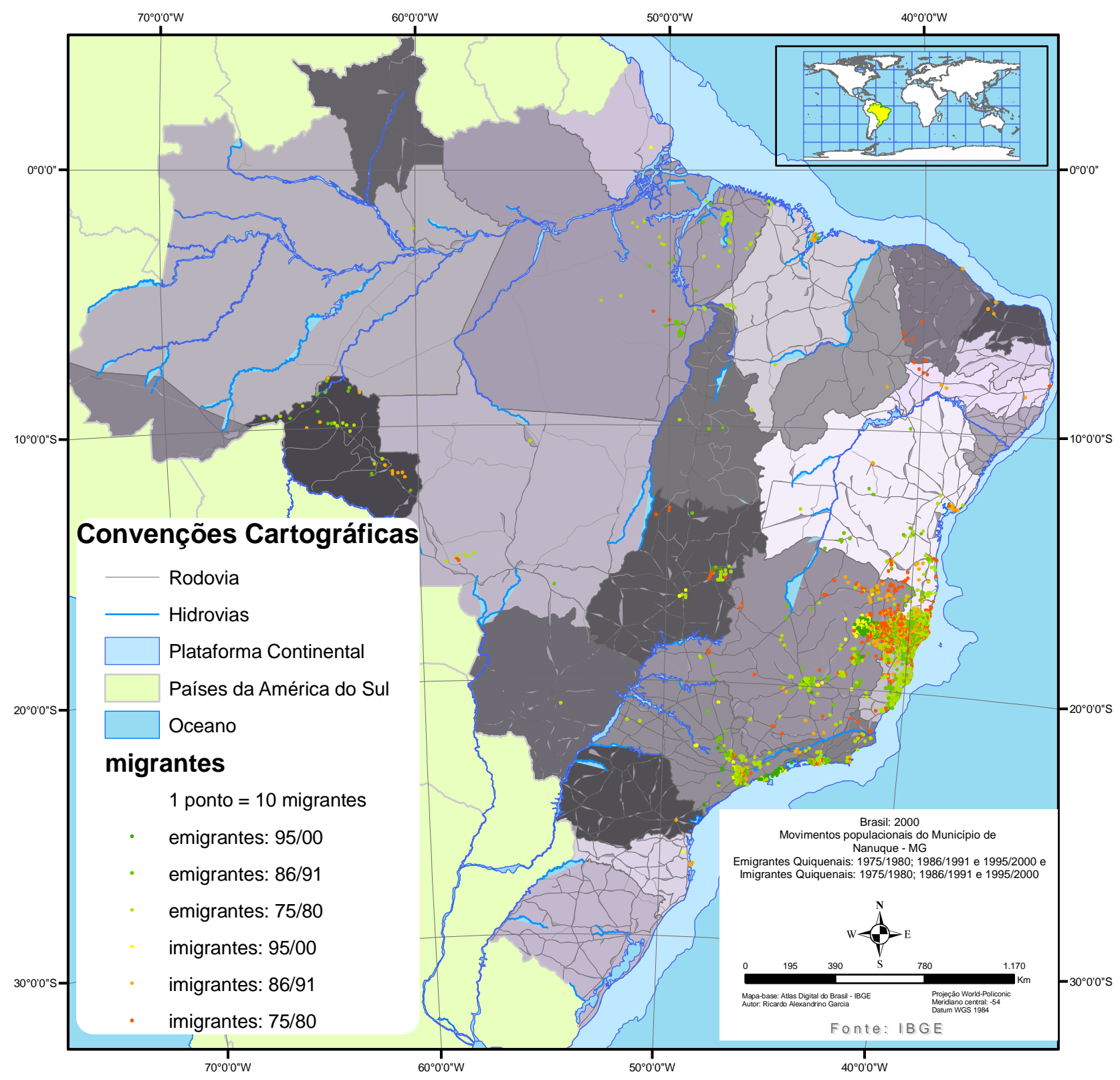

Fonte: IBGE. Censos demográficos de 1980, 1991 e 2000 (elaboração do autor).

Cadernos do Leste

Artigos Cientificos

Belo Horizonte, Edição Especial, 2000 a 2008 
Mapa 11. Brasil: 1975/2000. Emigrantes e imigrantes do município de Pavão, nos qüinqüênios 1975/1980, 1986/1991 e 1995/2000, segundo localidades de origem e de destino.

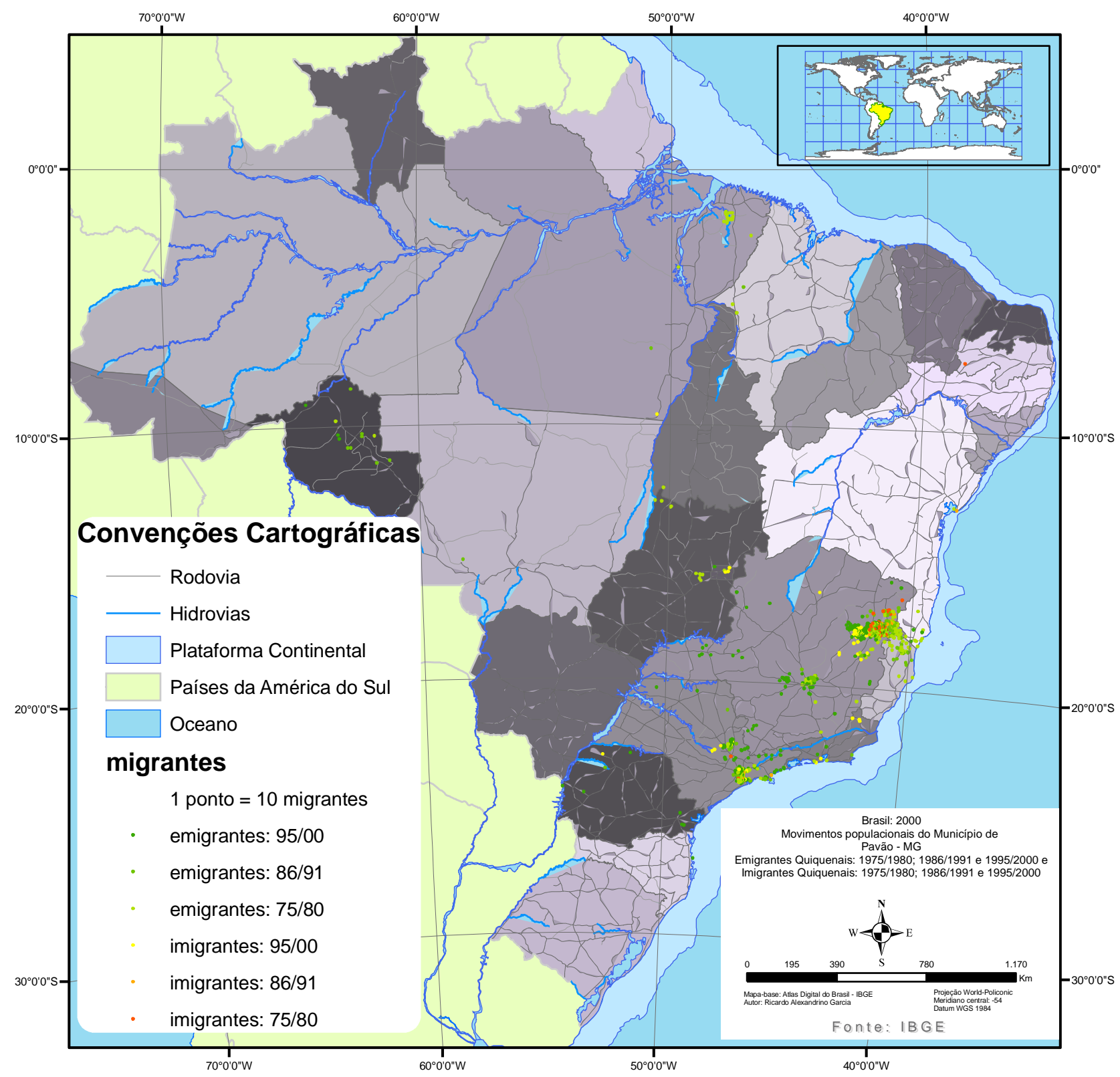

Fonte: IBGE. Censos demográficos de 1980, 1991 e 2000 (elaboração do autor).

Cadernos do Leste

Artigos Cientificos

Belo Horizonte, Edição Especial, 2000 a 2008 
Mapa 12. Brasil: 1975/2000. Emigrantes e imigrantes do município de Poté, nos qüinqüênios 1975/1980, 1986/1991 e 1995/2000, segundo localidades de origem e de destino. 


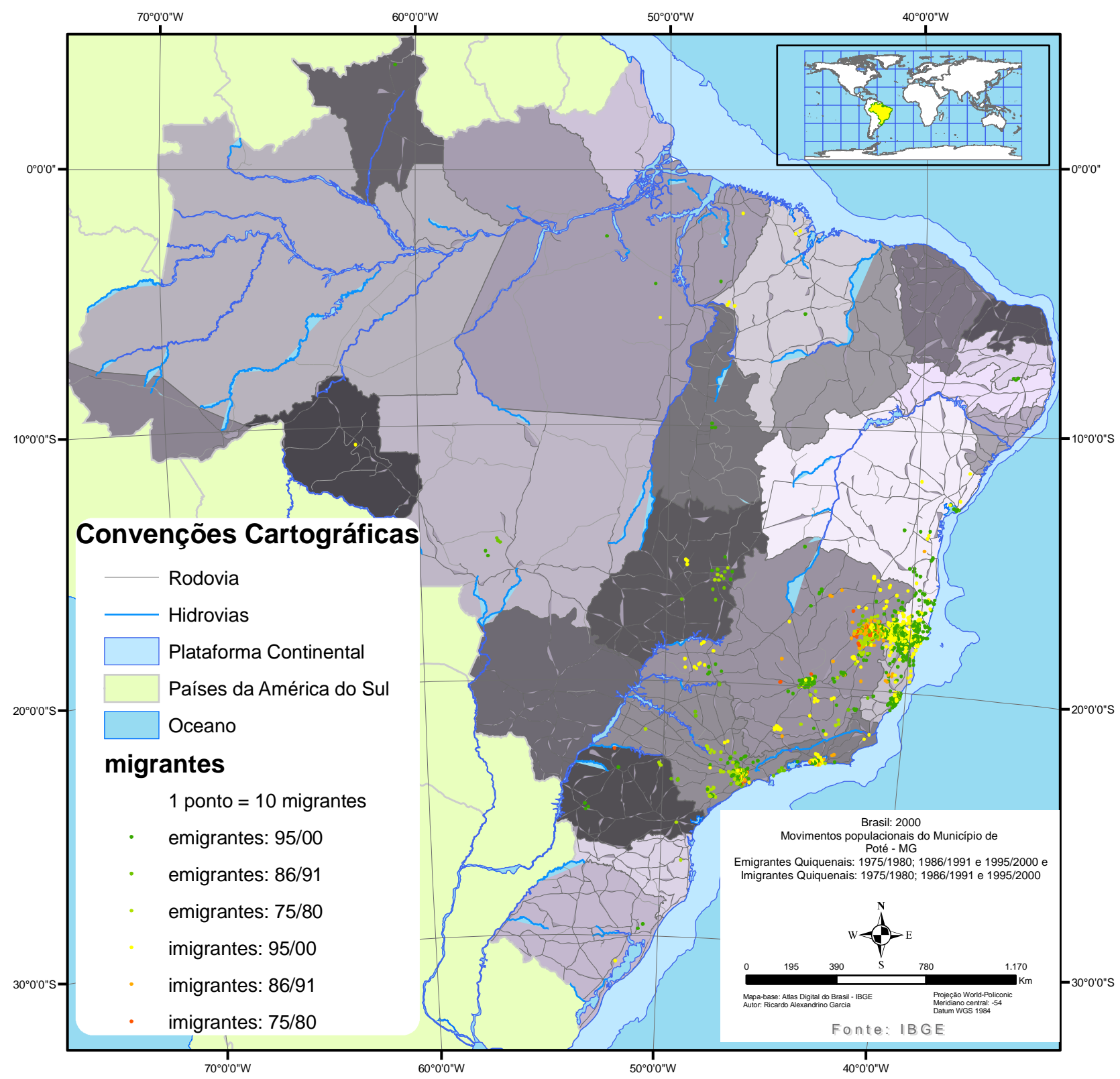

Fonte: IBGE. Censos demográficos de 1980, 1991 e 2000 (elaboração do autor).

Mapa 13. Brasil: 1975/2000. Emigrantes E Imigrantes Do Município De Serra Dos Aimorés, Nos Quinquênios 1975/1980, 1986/1991 E 1995/2000, Segundo Localidades De Origem E De Destino.

Cadernos do Leste Artigos Científicos 


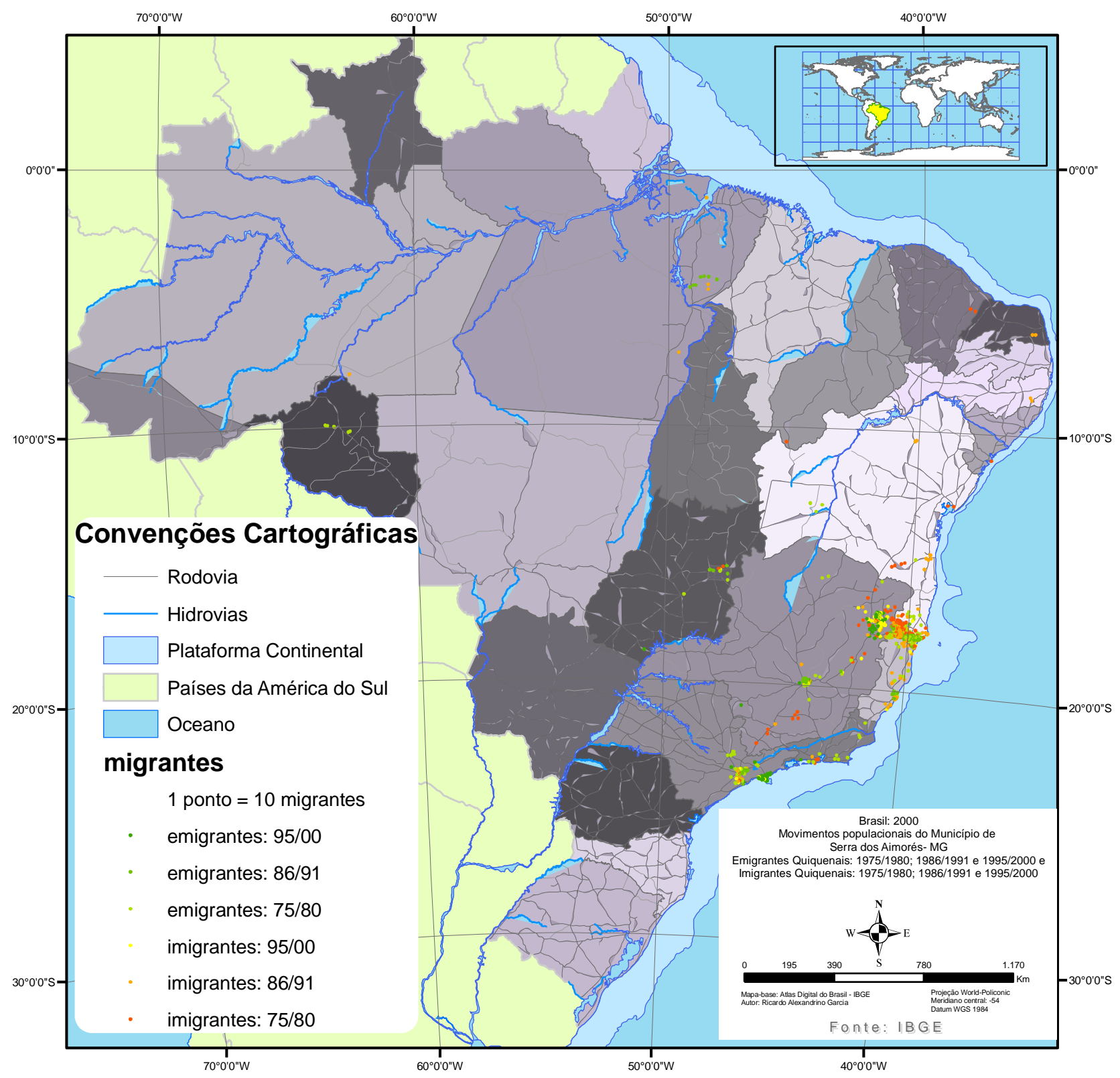

Fonte: IBGE. Censos demográficos de 1980, 1991 e 2000 (elaboração do autor).

O Mapa 14 traz a distribuição espacial dos fluxos migratórios do município de Teófilo Otoni e revela que na década de 90 houve poucos fluxos migratórios que ocorreram em torno do município e no estado de Rondônia. Em relação à Umburatiba, a análise do Mapa 15

Cadernos do Leste Artigos Cientificos 
revela que na década de 90 ocorreram muitos fluxos de imigrantes que se destinaram do sul de Minas e noroeste de São Paulo e muitos fluxos de emigrantes que se dirigiram para o norte do Espírito Santo e região centro-sul de Minas; observa-se também ocorrências de poucos fluxos migratórios na Bahia e em Rondônia. Já em Catuji, Mapa 16 que nessa mesma década muitos fluxos de imigrantes e emigrantes que envolviam as regiões metropolitanas de Minas e São Paulo foram verificados.

No tocante aos municípios de Novo Oriente de Minas e Crisólita, a distribuição espacial de seus fluxos migratórios estão tematizados nos Mapas 17 e 18. Pela análise dos movimentos populacionais do primeiro município, pode-se observar que durante a década de 90 ocorreram muitos fluxos de imigrantes que se destinaram do sul de Minas e noroeste de São Paulo e muitos fluxos de emigrantes que se dirigiram para o norte do Espírito Santo e regiões metropolitanas de Minas, São Paulo e Brasília; já a análise dos movimentos populacionais do segundo revela, por fim, que nessa década ocorreram muitos fluxos de imigrantes e emigrantes que envolviam as regiões metropolitanas de Minas, São Paulo e noroeste do Estado do Paraná. 
Mapa 14. Brasil: 1975/2000. Emigrantes E Imigrantes Do Município De Teófilo Otoni, Nos Quinquênios 1975/1980, 1986/1991 E 1995/2000, Segundo Localidades De Origem E De Destino. 


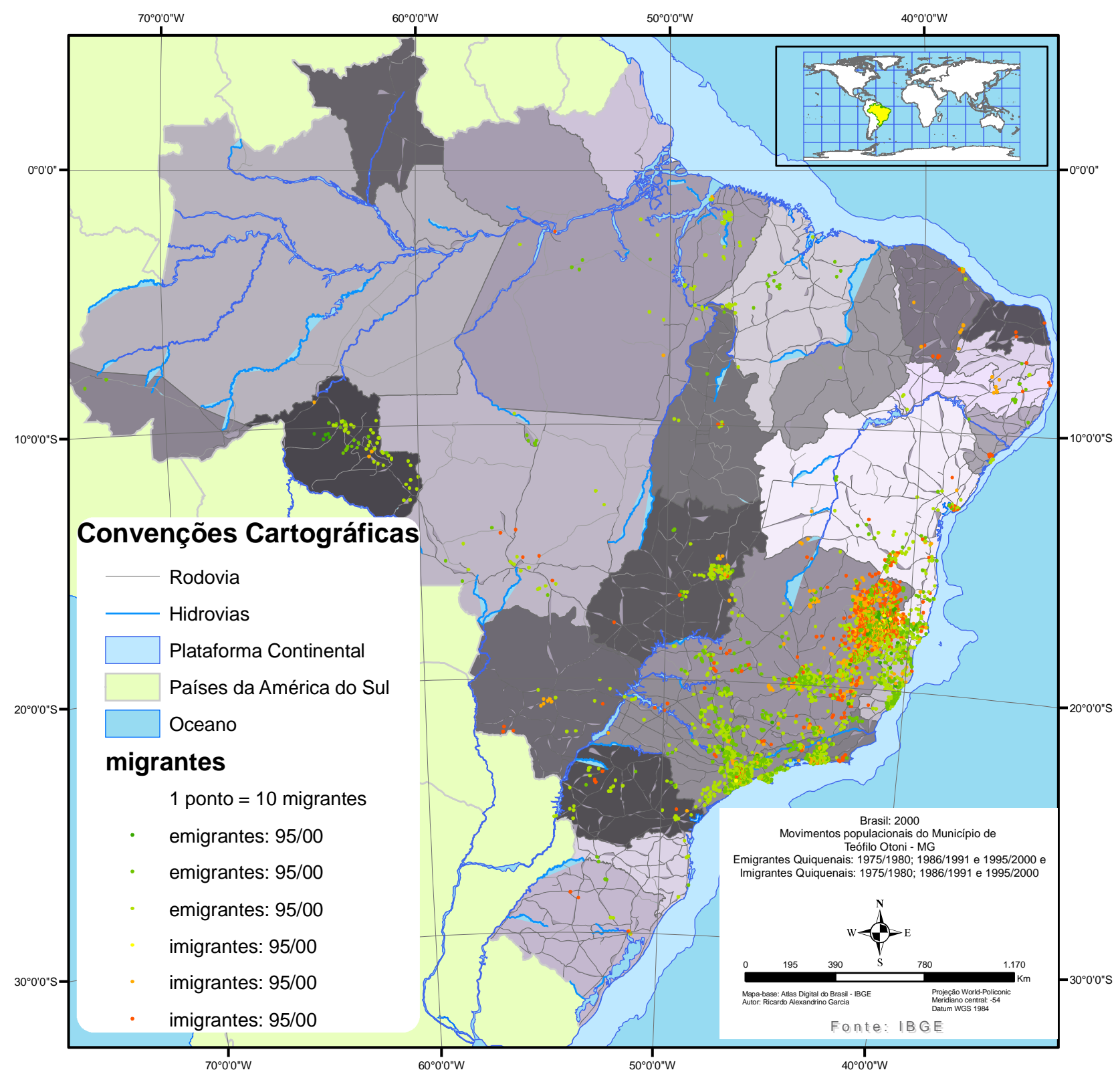

Fonte: IBGE. Censos demográficos de 1980, 1991 e 2000 (elaboração do autor).

Cadernos do Leste

Artigos Científicos

Belo Horizonte, Edição Especial, 2000 a 2008 
Mapa 15. Brasil: 1975/2000. Emigrantes E Imigrantes Do Município De Umburatiba, Nos Quinquênios 1975/1980, 1986/1991 E 1995/2000, Segundo Localidades De Origem E De Destino.

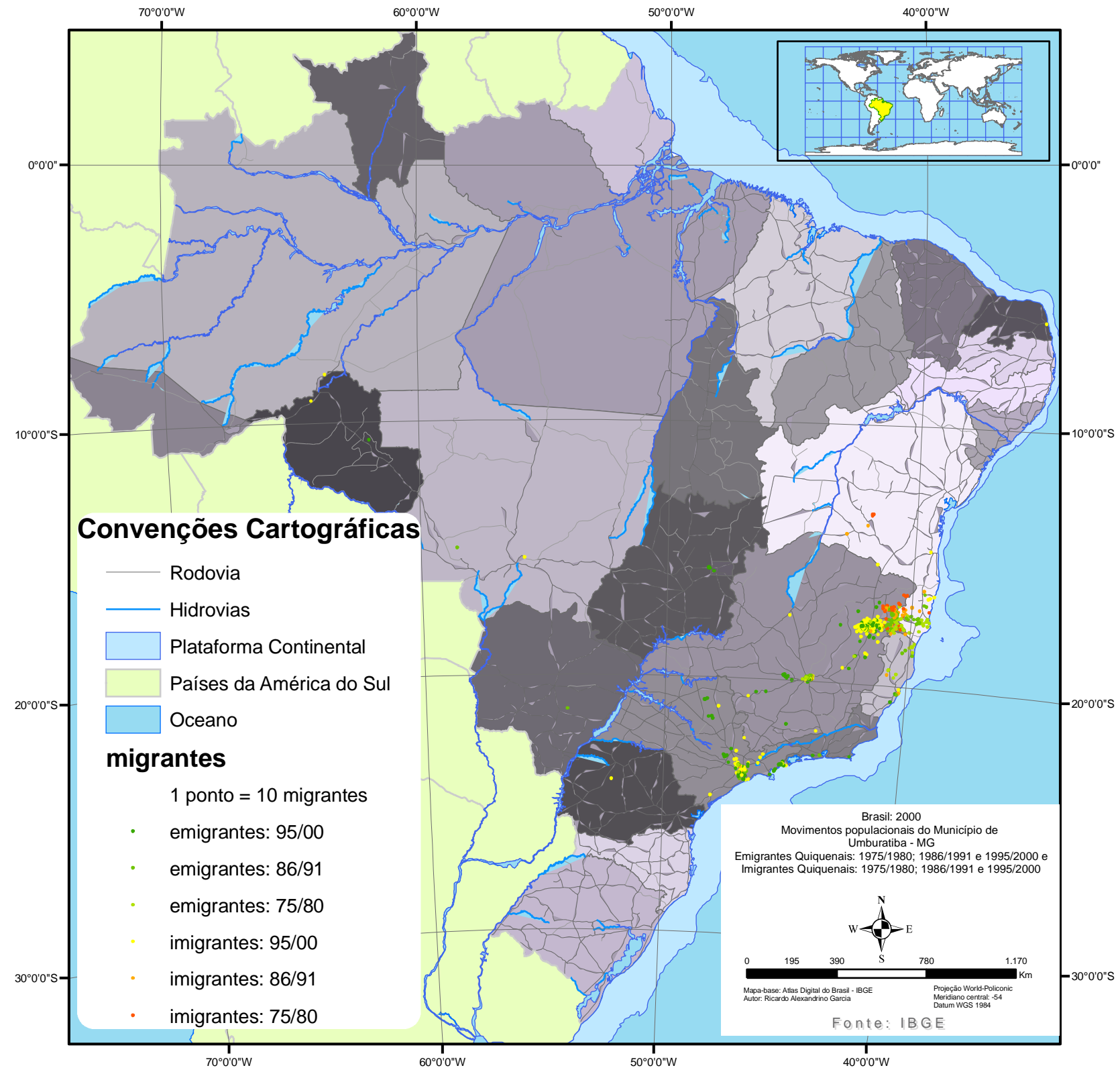

Fonte: IBGE. Censos demográficos de 1980, 1991 e 2000 (elaboração do autor).

Cadernos do Leste Artigos Cientificos 
Mapa 16. Brasil: 1995/2000. Emigrantes E Imigrantes Do Município De Catuji, No Quinquênio 1995/2000, Segundo Localidades De Origem E De Destino. 


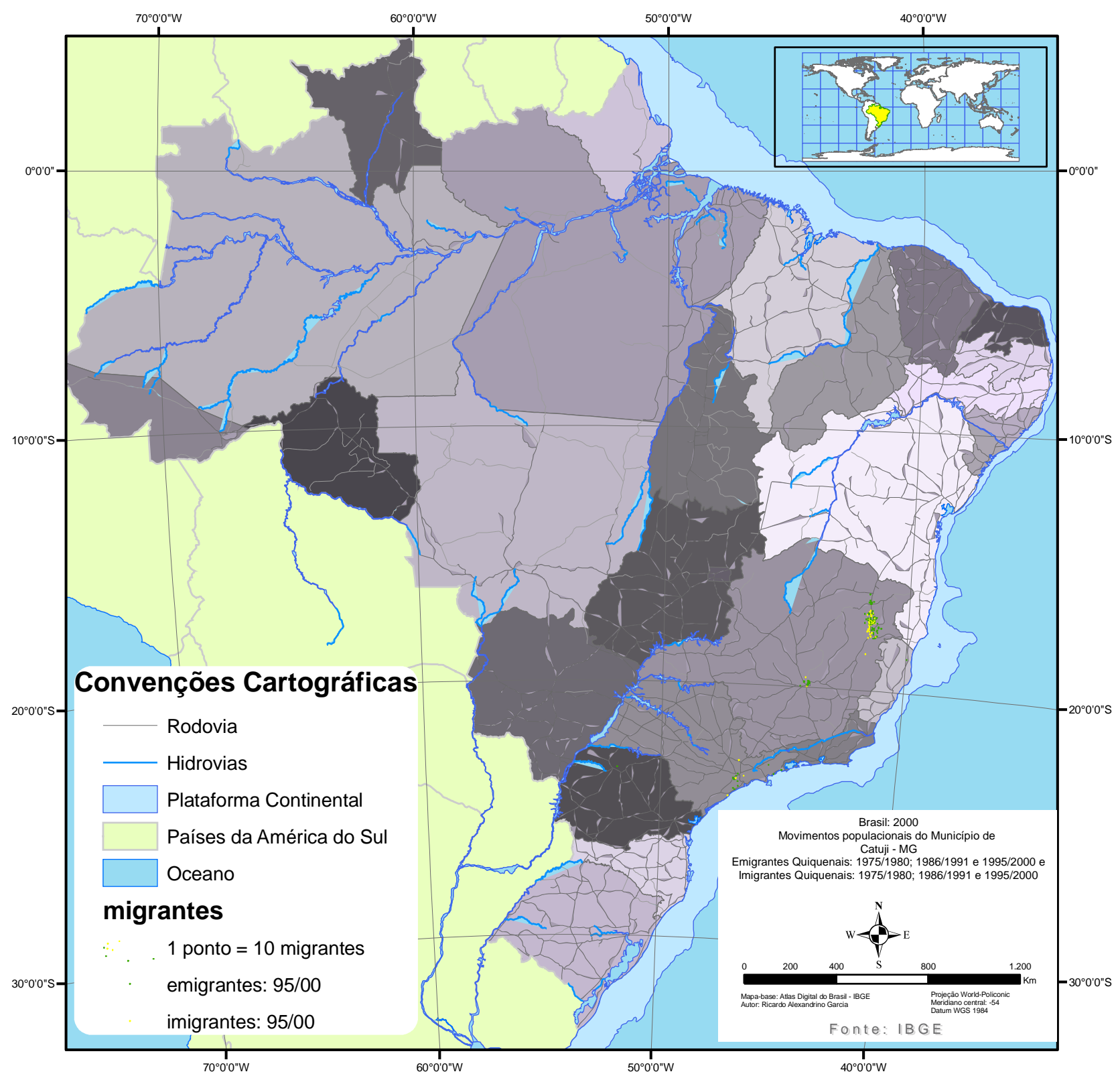

Fonte: IBGE. Censo demográfico de 2000 (elaboração do autor).

Cadernos do Leste

Artigos Cientificos

Belo Horizonte, Edição Especial, 2000 a 2008 
Mapa 17. Brasil: 1995/2000. Emigrantes e imigrantes do município de Novo Oriente de Minas, no quinquênio 1995/2000, segundo localidades de origem e de destino.

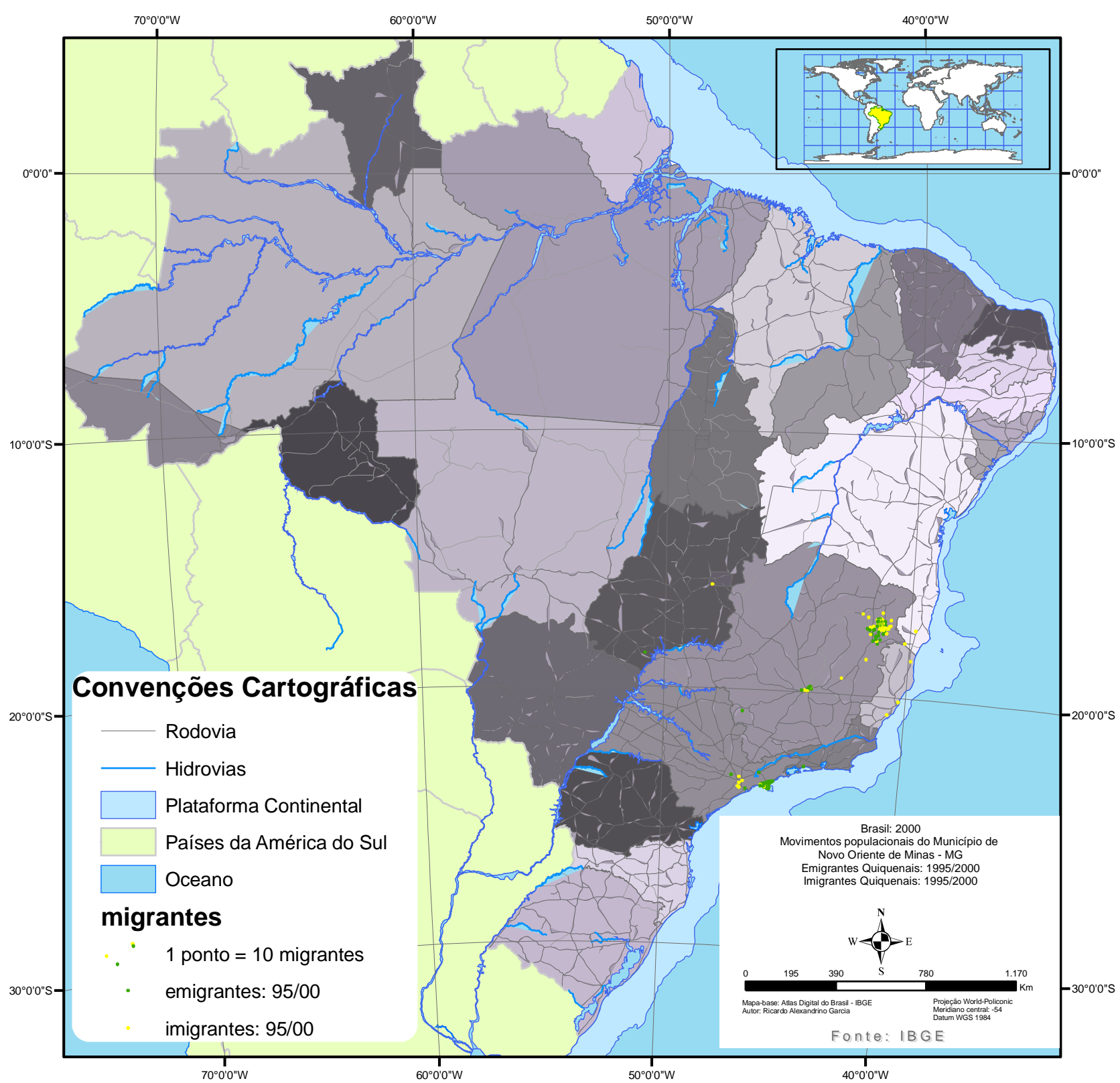

Fonte: IBGE. Censo demográfico de 2000 (elaboração do autor).

Cadernos do Leste Artigos Cientificos 
Mapa 18. Brasil: 1995/2000. Emigrantes e imigrantes do município de Crisólita, no quinquênio 1995/2000, segundo localidades de origem e de destino.

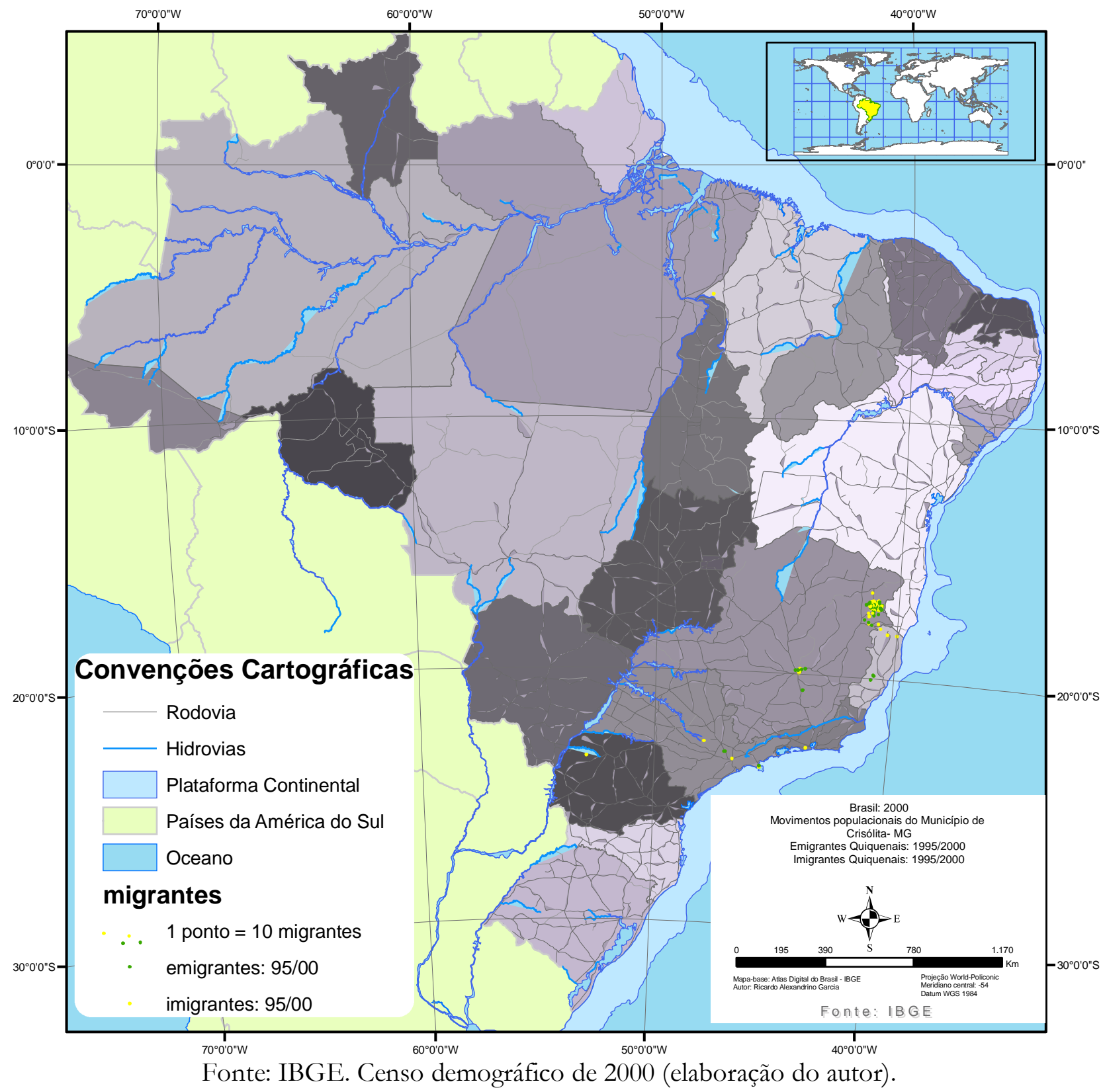

Cadernos do Leste

Artigos Científicos

Belo Horizonte, Edição Especial, 2000 a 2008 


\section{CONSIDERAÇÕES FINAIS}

O mapeamento da espacialidade dos fluxos migratórios dos municípios do Vale do Mucuri permite que se conheça, por um lado, o conjunto de cidades envolvidas nas diversas redes migratórias, responsáveis pela geração e manutenção dos movimentos populacionais captados pelos censos demográficos nas últimas décadas. Por outro, a demanda de instituições públicas e privadas pelo mapeamento e a atualização de informações desse tipo sugere que o planejamento territorial venha a se beneficiar com elaboração de diagnósticos mais específicos e detalhados, em seus diversos eixos.

Em Minas Gerais, por muitos anos, os estudos pioneiros das bacias hidrográficas abordavam prioritariamente as potencialidades hídricas para fins econômicos, quer sejam para a geração de energia elétrica, transporte, desenvolvimento da pesca, práticas de irrigação, entre outras. No período atual, o crescimento das atividades industriais associado à rápida urbanização exige do Estado a expansão de suas fronteiras comerciais o conhecimento de suas potencialidades sociais. A fase atual aponta, contudo, para a necessidade de se realizarem estudos mais detalhados, de acordo com o caráter estratégico que o planejamento territorial vem adquirindo desde o final do século passado.

Cadernos do Leste

Artigos Científicos

Belo Horizonte, Edição Especial, 2000 a 2008 


\section{REFERÊNCIAS BIBLIOGRÁFICAS}

AUGUSTO, Helder dos Anjos. Migração recente nas mesorregiões de Minas Gerais segundo os Censos Demográficos de 1991 e 2000. Tese de Doutorado. Belo Horizonte, MG. UFMG/Cedeplar. 2007. 232p.

BARBOSA, Waldemar de Almeida. Dicionário histórico-geográfico de Minas Gerais. Belo Horizonte: Promoção-da-Família Editora, 1971.

CARVALHO, José Alberto M. de \& Garcia, Ricardo Alexandrino. Estimativas decenais e quinquenais de saldos migratórios e taxas líquidas de migração do Brasil, por situação de domicílio, sexo e idade, segundo Unidade da Federação e Macrorregião, entre 1960 e 1990, e estimativas de emigrantes internacionais do período 1985/1990. Belo Horizonte: CEDEPLAR/UFMG, 2002.

CERQUEIRA NETO, Sebastião Pinheiro Gonçalves de. Contribuição ao estudo geográfico do município de Nanuque (MG). Caminhos de Geografia - revista on line, Uberlândia, v. 9, n. 15 , p. 82-92, jun. 2005.

DUARTE, Regina Horta. Notícias sobre os selvagens do Mucuri. Belo Horizonte: Editora UFMG, 2002.

- Olhares estrangeiros: viajantes no vale do rio Mucuri. Revista Brasileira de História, São Paulo, v. 22, n. 44, 2002.

FONSECA, Ivan Claret Marques. Nanuque: seu povo, sua história. Brasília-DF, 1985.

FUNDAÇÃO JOÃO PINHEIRO - FJP. A colonização alemã no Vale do Mucuri. Belo Horizonte, FPJ, 1993. 161 p.

LOPES, José da Paz. Minas, o século XIX, Teófilo Otoni e progresso econômico. In: III Seminário sobre a cultura mineira no século XIX. Belo Horizonte: Conselho Estadual de Cultura, 1982. 
MOURA, Antonio de Paiva. O Jequitinhonha e o Mucuri na história de Minas. Movimento de Educação de Base, Brasília. Disponível em: <http://www.meb.org.br/biblioteca/culturaminas4>. Acesso em: 28 fev. 2007.

RIBEIRO, Eduardo Magalhães. Imigrantes, fronteira e agricultura nas matas do vale do Mucuri - Minas Gerais. Travessia : Revista do Migrante, São Paulo , v.17, n.48 , p. 9-14, jan./abr. 2004.

RIGOTTI, José Irineu R. (1999). Técnicas de mensuração das migrações, a partir de dados censitários: aplicação aos casos de Minas Gerais e São Paulo. Belo Horizonte, 1999. CEDEPLAR/UFMG. (tese de doutorado). 